\title{
Taking advantage of Fibonacci's series to support the psychological aspect of some cancer patients
}

\author{
Dr. Maysa Fekry Al Sayed ${ }^{1}$ Dr. Maha Mahmoud Ibrahim ${ }^{2}$ Eng. Shaimaa Sayed Kassem ${ }^{3}$ \\ 1) Full-time Design Professor, Textile Printing, Dyeing and Processing And former head of the scientific department - Faculty of Ap- \\ plied Art - Helwan University \\ 2) Professor of Interior Design and Furniture - Faculty of Applied Art - Helwan University \\ 3)Assistant Lecturer of Textile Printing, Dyeing and Processing - Faculty of Applied Art, Helwan University
}

\section{KEY WORDS:}

Fibonacci Series, Design, Textile Printing, Cancer Adjunctive Therapy.

\begin{abstract}
:
This research is directed to the analytical and experimental study of the Fibonacci series in a contemporary artistic way that can lead to a new trend in the design of textile printing in general in modern ways that add diversity in the color groups and the multiplicity of different sensory and visual effects by achieving balance in shape, color, energy and function in order to obtain positive energy that helps to increase the performance of human vital functions to support the psychological aspect of some cancer patients. And getting to know the concepts of Fibonacci series and their technical analysis and application with respect to the design of textile printing.
\end{abstract}

\section{INTRODUCTION:}

The beauty that the eye perceives around humans starting with the galaxies and planets and reaching the shapes and the colors of flowers is something that forces the mind to believe that there is no coincidence in this universe, and that there are ties that binds them, which may be supported by the fact that mathematics has a deep and mysterious connection with nature so that we may even say that nature speaks mathematics[1].

Mathematics has been associated since the dawn of time with nature, beauty and harmony, as Pythagoras said, "Everything is arranged according to numbers", and as others have said: "The essence of physical truth is linked to numbers, and beauty exists on mathematical pillars". International standards in mathematics education have long called for the need to find associations of mathematics with other fields. A remarkable role in the scientific and technological progress that the world is experiencing today has extended its various uses to include many applied fields in the social and human sciences and it's the corner stone of any scientific or technical progress, mathematics today is not seen as an independent science, but in all aspects of knowledge and everything we can think of.
The relationships between art and mathematics have become increasingly clear as they reveal inherent facts in nature, for example, the symmetry of flowers, the fractals, and the arterial system in the human body. Mathematics is not only in biology, chemistry and physics, but also in art, music, architecture and design as in engineering sculptures and computer graphics. To transmit all visual phenomena to the connoisseur audience, allowing people to understand the things surrounding them or even within themselves [2].

\section{OVERVIEW AND BACKGROUND:}

There are hidden forces beside mathematics that move everything in the universe and connect the human with his surroundings, so the science of qualitative physics tends to study those levels that are not on the physical realm with respect to the concept of energy based on numbers, mathematical series and golden ratios, human that lives at these different levels of energy is produced influencing and also is influenced by those levels of energy. Based on this the process of fabrics printing is reaching beyond its perceived influence into new dimensions which are not a part of the physical plain hence producing a form of energy[3] affecting the human being energy levels and his health, and 
its use to support the psychological aspect of some cancer patients. The nature of the materials used in the printing, dyeing and processing of fabrics, to which patients are exposed, mainly affects the quality of energy emitted.

\section{First: What is Fibonacci's series:}

Fibonacci's seriescomes with Leonardo Fibonacci raising a question about rabbit breeding, findthe result presented by Fibonacci was the following consecutivenumbers:(1, 1, 2, 3, 5, 8, 13, 21, 34, 55.... Etc.)[4]. This order, which is that each number represents the collection of the two previous numbers, and the (Fn) seriesof Fibonacci number is known as the mathematics description of the recurring relationship (en)

$$
\mathrm{Fn}=\mathrm{Fn}-1+\mathrm{Fn}-2
$$

with the resulting values

$$
\mathrm{F} 0=0 \text { and } \mathrm{F} 1=1[5]
$$

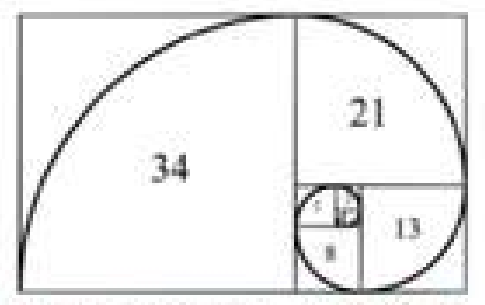

$0+1=1$

$1+1=2$

$2+1-3$

$3+2=5$

$5+3-8$

$8+5=13$

$13+8=21$

$21+13=34$

$34+21=39$

$55+34=82$

Q, $1,1,2,3,5,8,13,21,34,55,89,144-89+55=144$

Figure 1. Shows the Fibonacci series, source : (https://arincen. com/forex-text-academy/16/74(11/8/2019))

It was proven later to be a series of serial numbers that were useful in many different mathematical and scientific uses. And there's a Fibonacci series in Apps Many, for example, in the rings of the normal snails, in the growth of germinations and in the beehive, and in a very famous number called the golden spring.

In addition to the conventional gold ratio of 1.618and Fibonacci $(1,1,2,3,5,8,13 \ldots$. Etc.) which depends on the total of the previous two numbers gives the following number, an understandable ratio was found linked to the effect of this ratio in introducing balance energy and finding the basic components of regulated energy within the design, if these numbers are used in the creation of repetitions or ratios or angles the regulated energy is found in The design, which gives rates that correspond to different uses, has been found to be a resonant relationship and a correlation between numbers and life functions[6] .

Fibonacci apps:

\section{Fibonacci Rectangle}

The Fibonacci rectangle is a method of representing a geometrically Fibonacci series, as it is obtained in a Fibonacci series if two adjacent squares along the rib are drawn in one unit, then a square 2 unit length $(1+1)$ is drawn to be structured on two adjacent squares, and then a square with a rib length of 3 units $(1+2)$ is drawn on the Two previous squares and so on ... As in form (2)

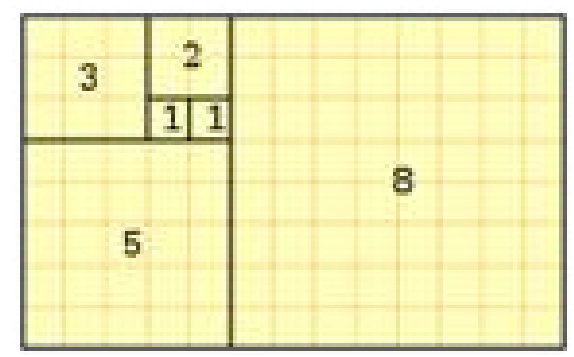

Figure 2 . Shows the Fibonacci rectangle, the source: (https://www.3lomsena3at.net/4001.html(13/8/2019)

If a quarter of a circle is drawn in each square respectively, a spiral shape form (3) arises, and the spiral shape made in the golden rectangular squares makes lines of the center increasing with the coefficient of the golden ratio, i.e. the points on the coil are 1.618 times from the center after a quarter of a cycle.
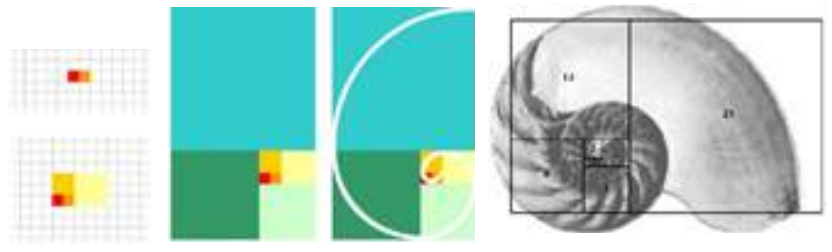

Figure 3. The graph of the Fibonacci rectangle and its match with its shell shows the source: ((https://www.3lomsena3at.net/4001. html(13/8/2019)

\section{Golden Triangle}

There is another way to get a gold ratio, and that is by building an equilateral triangle so that the angle of the head is equal to (36)degrees, and the angles of its base equal to (72) degrees[7] as in figure 4.

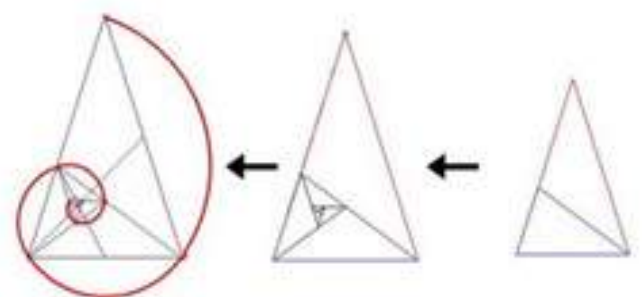

Figure 4. Shows the Fibonacci triangle, the source(https://www. 3lomsena3at.net/4001.html(13/8/2019) 
The search for proportions and their impact may not be interrupted, but may go from one stage to another from a search for beauty only to a search for beauty and the introduction of balance that has an impact on people's health and the regularity of the cosmicsystem[8]. The design language of textile printing with its components of shapes and colors must be expanded to include levels that interact with different energy in order to balance it, thereby reaching the bio-balance of the human being and making it immune to the pollutants surrounding it.

\section{Second: Fibonaccisuccessiveapplicationsinnature}

Nature is the greatest and most complete source from which man can study and learn, it is the largest and most general objective source of the realm of the realm of the realm of the realm of the world's laws as a result of its containment of many aspects of life, in which man can realize the divine harmony in the universe in which the sources of the energy organized for life are settled[9].

Sometimes in nature, we can see the occasional hurricane-based Fibonacci, as well as some spiral galaxies, Some flowers such as sunflowers, plants and fruits such as pineapples, pine cones, snail shells, the human ears shape, and we find that the longitudinal palm of the human hand achieves the golden ratio, and the phalangesof hands as well.
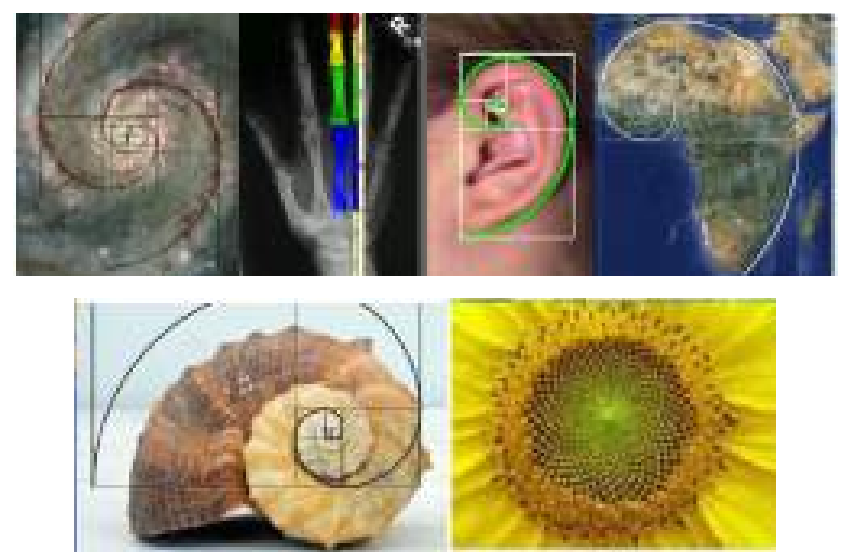

Figure 5. Shows Fibonacci's series in nature, the Source: (https:// www.google.com/image(14/8/2019))

In the old days, the ancientGreeks many of their drawings, and the architectural designs relied on the golden ratio such as the (Temple of the Parthenon) and the Fibonacci series[10], and was used by Leonardo da Vinci in His famous painting "Monalisa", as it appeared in some musical works, perhaps intentionally or unintentionally. Engineering and its qualitative concept have been associated with symbolism in many of its appli- cations.

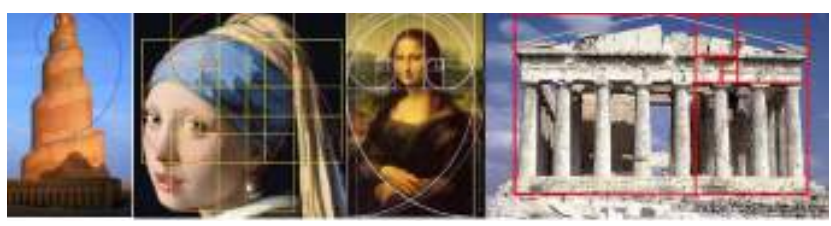

Figure 6. Demonstrates Fibonacci's series in ancient civilizations، Source:https://www.google.com/image(14/8/2019)

The balance of shapes in nature is different from that of itself[11].Where's that? Natural sciences confirm that human beingsand all theirsurroundings is a form of energy that takes forms as It's. All objects of all shapes and sizes create within them an atmosphere of power and a special area of energy, and this particular area either increases the natural sphere of power or equals it or reverses it, the cone, the pyramid, the ball, the cube and other various natural forms act as instruments for modifying the frequency of the universe's energy[12].

Also, the natural phenomena of Fibonacci and the Pyramids of Giza in Egypt where the length of the rib of the pyramid is 783.3 feet .... Any 238.7 meters, the height of the pyramid is 484.4 feet...... That is, 147.6 meters, if we divide the length of the arm at the height of the pyramid, the result is 1.618 , which is the magic Fibonacci number. Scientists say that the ancient scholars of the Egyptian era knew these figures and their secrets as they were very superior in mathematics and astronomy[13].

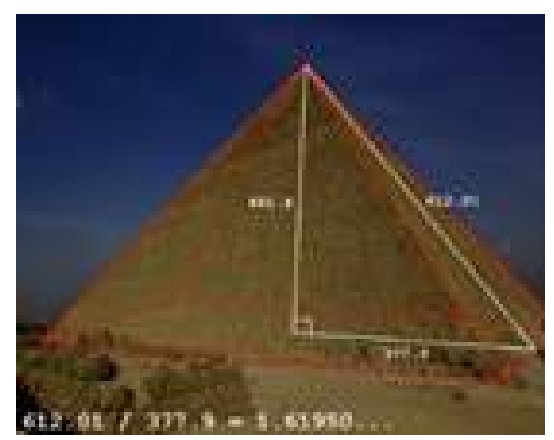

Figure 7. Shows the golden ratio in the Great Pyramid, Source:(http://arab-hams.com/home.php?page=3\&lang=ar\& id $=6012(14 / 8 / 2019))$

Nature takes different and varied forms and if it takes dimensions in the void surrounding it has aesthetic qualities according to its compositional systems, this pure beauty is linked to its mathematical and engineering forms, for example the beehive, it is a hexagonal prism with an open or incomplete end, and it has a higher end. With three surfaces in the form of a desig- 
nated, or crystals are subject to the laws of geometric composition and grant the status of beauty to these bodies, these examples also which are based on these compositions of the logarithmic snail, which is one of the most common forms in nature, represented by shells and snails, and these shells are subject to onefixed mathematical law that never changes[14].

\section{Third: The relationship between Fibonacci's series} and energy:

Modern science has a passion for detecting the applications of the golden ratio and the Fibonacciseries, and for many discoveries it is possible to assume that man lives within the world of Fibonacci. These series overlap in all walks of life, in plants, animals, music, the arts, astronomy, theoretical physics and crystal sciences, physics, high-energy particles and many more that lead to the material world based on the rule of goldratio[15].

Energy is the ability to cause action or effect, but this definition does not include the precise concept of different energies, and the word energy expands to include vital, sensory, intellectual and spiritual energy, everything in the universe is energy even solid matter is in fact a particular image or state of energy, and in qualitative physics we are one with nature.Each element of the universe has one constant frequency, and the frequency is its wavelength, its radiation energy, color and character, and when the element turns into a compound, the radiation energies overlap together and a major energy is the sum of the energies of the elements involved in the composition of this compound. Things are complicated in the primary organisms, then the plant and the animal until they reach the human who has a sophisticated nervous system and the greatest amount of qualities and characteristics[3].

Energy is closely related to man, and it is the main driver, without which human life ceases. There are many energy sources that supply the human and help him to perform its vital functions, including the apparent and known as the energy that helps him to move, there is an invisible energy that communicates with the cells together, and there is another type of micro energy that runs in the paths and points of its own which is known as energy vitality,whichis the invisible part of our bodies when they react negatively to the harmful energy types found in thesurrounding environment, creates imbalances and imbalances in the energy functions of the body's organs and thus causes diseases[3].

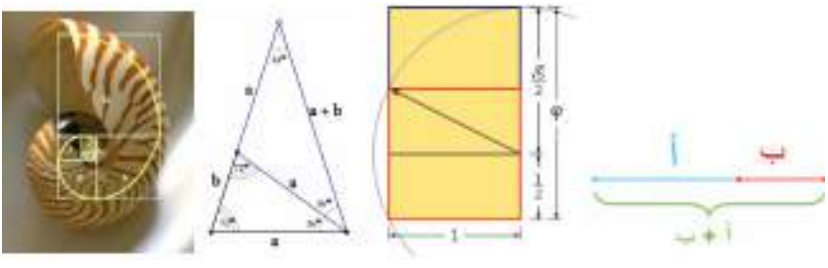

Figure 8 . Shows the golden ratio in both the golden rectangle, the golden triangle and the Fibonacciseries in the snail, the source: (http://magazine.8pixel.co/2017/05/27/golden_ratio/)

The positive energy generated by a series of consecutive Fibonacci numbers is $(1,1,2,3,5,8,13 \ldots$ etc.), while the gold ratio is the result of dividing each number by the previous number, this series is unique to many characteristics, including the relationship with the golden number. ' So if each number of series is divided by the number that precedes it $(1 \div 1=1,1 \div 2=2$ ' $2 \div 3=1.5$ ، $3 \div 5=1.6660000$ ، $5 \div 8=1.6$ ، $8 \div 13=1.625$ ، $13 \div 21=1.61538$ ،...) Note that it is gradually approaching the number1.618034, which is called the conventional gold ratio of 1.618 .

The relationship between Fibonacci series and energy within textile printing design may be linked to the effect of this ratio in introducing balance energy and finding the basic components of regulated energy within it, if these numbers are used in these iterations, ratios or containers, the regulatory energy is created. In design, which gives rates that correspond to different uses, the a above can have positive properties in influencing human bioenergy as an important factor in increasing human immunityfunctions to support the psychological aspect of some cancer patients.

Fourth: materials used to design textile printing and its relationship to bioenergy (environmentally safe fabrics and printing plastics):

One of the most important foundations used for the success of textile printing design is the choice of the material used to apply the product, given that the capacity of the materials used has a significant impact on the capacity of the design as a whole, and since the research speaks mainly to the design of textile printing The first thing that comes to mind is the material of cloth, pastes and natural pigments used as the main raw materials in the textileindustry[16].

The development of the industries has led to the emergence of various types of raw materials, processing materials and chemical tins to improve or modify the properties of the raw materials in accordance with the needs of the consumer, but this progress has partially overlooked the attention to the properties that 
negatively affect the environment polluting the water drains in addition to their negative impact on human health caused by cancers and allergies[17].

The nature of the raw materials used mainly affects the quality of the energy from which they are produced, natural materials such as cotton, wool, linen or natural silk ... Etc. has a good effect on vital energy, because it originally came in a living organism, grew and interacted from the universe around it, breathing from the air and sucking its food from the same earth on which we live, it carries the qualities of the qualitative energy of the universe, and on the contrary the effect on Industrial raw materials.

A person is exposed to a range of effects that affect his vital balance and activity, which can be negative, disrupting his functions and causing his imbalance. One of the most important of these effects is environmental pollution, which can lead to a change in the foundation of the body's cells, changes in gene composition and many serious diseases. Materials containing processed and artificial fabrics and chemical formulations that are very harmful to human health.

As for the natural colors derived from some of the different natural plants, the strength in the simplest possible way, the least expensive and harmful to the environment and then used in dyeing different natural fabrics. Improving the various stability properties, especially the stability of the washing of natural fibers dyed with natural environmentally friendly pigments, instead of the use of mineral salts and their harmful effect on the environment[18].

Most of the methods of processing and processing of fabrics are also considered to negatively affect the environment and human because of the use of harmful chemicals and carcinogens in these treatments, scientific research has been directed to search for safe and environmentally friendly processing materials, for example, ketosan(CHITOSAN).) It was used on cotton and worked to increase its absorption of colors and is an antimicrobial agent and could inhibit the growth of bacteria[19].

As an example of one of the methods of printing on cotton, the removal printing agent, itis the most widely used and most diverse method used to introduce design to textile fabrics. The removal factors used are oxidized or reduced to acids, acids, alkalis and various salts.
However, the most important methods of removal depend on formaldehyde sulfate and the uria dioxide. More recently, environmental and industrial safety concerns have increased the possibility of using enzymes in textile manufacturing to ensure environmentally friendly production. However, it is highly toxic and produces formaldehyde, a carcinogen known to humans. Removal of textiles[20]. Using all the natural components of a successful and environmentally safe textile printing design, to reduce environmental pollution, increase positive energy, and raise human health immunity to endemic and carcinogenic diseases that increased with the industrial revolution.

fifth: The functional dimension ofthe energy generated by the Fibonacci series in textile printing design: Positive energy is the inner spirit that a person feels when he is psychologically comfortable, where he feels that he has the energy to move in life and towards the better future, where all this derives from the spirit of optimism and happiness, exposure to art can significantly improve statistically Spiritual well-being in cancer patients, especially females, during active oncology treatment, it makes a connection between artistic creativity and spirituality, indicating that there is a relationship between the mind and the body, and the results showed that exposure to art can reduce emotional distress while enhancing the psychological factor, and It's clinically important, it helps get rid of pain or discomfort[21].

Cancer is a terrible disease that many fear to mention, and talking about it has not become a modern limited to specialists, but it has become the talk of the general public, and we are interested in this field cancer, and it is believed now 80 to $90 \%$ of all cancer cases are directly or indirectly due to environmental factors and the remaining few are where genetic factors play a role in facilitating the incidence of cancer[22].

Art therapy is a type of complementary therapy that supports to improve the quality of life of cancer patients, to affect the whole person in a positive way by taking care of the discharge of the patient's negative energies, and help to create new positive energies that strengthen the immune system, and create a capacity New to the patient to accept treatment, which helps to speed up the healing process not to mention the opening of new energies of hope and happiness that already accelerate healing, enhance its ability to face cancer, 
heal emotions by externalization, and enhance its energies and self-identity[23].

The structural foundations of the design of the elements used and colors in art therapy can improve the mood and be a calming activity to relax and provide a sense of control, increase self-esteem and be a supportive environment, and have positive results in raising the morale and therefore The body's immunity and increased ability to resist the disease, where studies have shown that while using the aesthetics of textiles help women with breast cancer to focus on creating something beautiful and overcome the negative mood, and control Anxiety and depression, therefore art can be a distraction from negative emotions it serves as an effective mood fix[24].

Color is an important element with direct impact on the human being, such impact may vary depending on the nature of the recipient himself in terms of his or her culture, nationality and personal preferences, and each person has his or her favorite color group, which may vary from person to person, regardless of their different circumstances and social environments. and cultural.

But there are some colors that may be similar to their meaning and effect on most recipients, and these points can be used to develop some color foundations that can be followed in the work of designing textile printingfor each color energy and consequently a certain effect on our bodies The concept of color healing depends on providing the body that suffers from a defect, whether organic or psychological, a return of the color that detracts from it or whose energy changing the negative attitude to a positive attitude. Or change negative emotions to positive feelings.

For example:

\begin{tabular}{|c|c|c|c|c|c|c|c|}
\hline \multicolumn{7}{|c|}{ Table (1): Shows Colors and Effect of color in the treatment of certain diseases } \\
\hline Color & Violet & Indigo & Blue & Green & Yellow & Orange & Red \\
\hline $\begin{array}{c}\text { Effect of } \\
\text { color in } \\
\text { the } \\
\text { treatment } \\
\text { of certain } \\
\text { diseases }\end{array}$ & $\begin{array}{c}\text { helps to } \\
\text { activate } \\
\text { inspiration, } \\
\text { automaticity } \\
\text { and spiritual } \\
\text { and physical } \\
\text { balance }\end{array}$ & $\begin{array}{c}\text { Treatment } \\
\text { of visual } \\
\text { disorders }\end{array}$ & $\begin{array}{c}\text { Relieve } \\
\text { mental } \\
\text { stress and } \\
\text { help stop } \\
\text { bleeding } \\
\text { and de- } \\
\text { stress }\end{array}$ & $\begin{array}{c}\text { Used in } \\
\text { cases of } \\
\text { bone } \\
\text { fracture } \\
\text { and } \\
\text { regrowth } \\
\text { of dead } \\
\text { cells in } \\
\text { the body } \\
\text { in general }\end{array}$ & $\begin{array}{c}\text { Used to } \\
\text { stimulate } \\
\text { the } \\
\text { intellectual } \\
\text { and mental } \\
\text { level of the } \\
\text { body, and } \\
\text { to process } \\
\text { skin } \\
\text { diseases }\end{array}$ & $\begin{array}{c}\text { Used to } \\
\text { boost and } \\
\text { increase } \\
\text { immunity } \\
\text { to the } \\
\text { body, and } \\
\text { helps treat } \\
\text { chest and } \\
\text { kidney } \\
\text { diseases }\end{array}$ & $\begin{array}{c}\text { Treatment of } \\
\text { certain blood } \\
\text { diseases, } \\
\text { circulation, } \\
\text { frustrations } \\
\text { and } \\
\text { depressions }\end{array}$ \\
\hline
\end{tabular}

the study used it in most designs tosupport the psychological aspect of some cancer patientsinside Bahia Hospital And they get high positive energy.

The following is an application of some of the print designs that are based on the Fibonacci series:

From the above it is clear that the mathematical relationships of the elements and units used redundant are one of the most important foundations of design that achieve balance, proportion and proportionality between them, as those sports relationships such as successive numbers Fibonacci generate positive energy resulting from the launch of the golden ratio among their numbers, This has been used in the design of textile printing where the plastic elements, whether natural, engineering or heritage arts, have been introduced in a regular frequency tracked in successive sizes Fibonacci and the use of colors with appropriate frequencies in order to generate positive energy that increases and increases immunity Cancer patients in general and patients of Bahia Hospital in particular in order to employ these designs to serve the community as print suspended fabrics and women's fabrics, and for this study the following design experiments (self-experience of the study): 


\section{Design Experience (1)}

\begin{tabular}{|c|c|c|}
\hline Items used & Artwork & Recruitment \\
\hline
\end{tabular}

Unit used: Islamic cup was repeated and distributed in proportion to the Fibonacci series

Functional dimension: Design of print suspended fabrics inside one of bahia hospital's detection rooms

\section{Design Experience (2)}

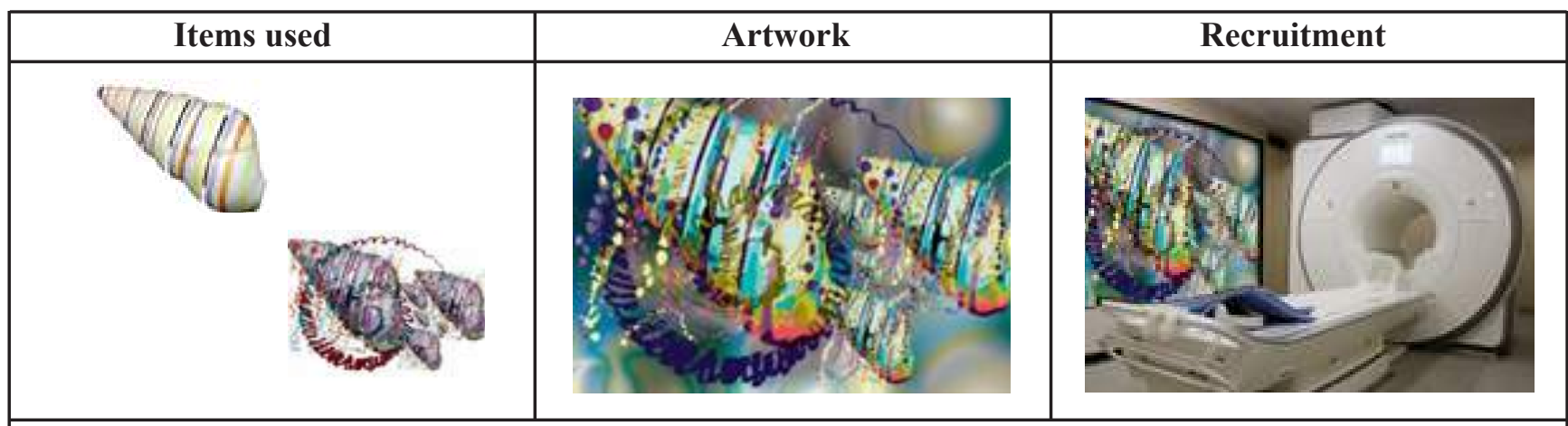

Unit used: Cochlear has been repeated and distributed in proportion to the Fibonacci series

Functional dimension: Design of print suspended fabrics inside one of bahia hospital's detection rooms
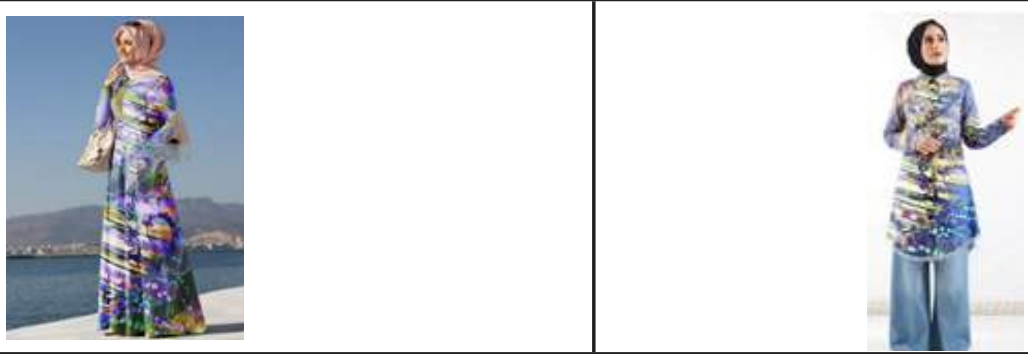

Functional dimension: Print design for morning women's fabrics in general and women with cancer patients in particular

\section{Design Experience (3)}

\begin{tabular}{|l|l|}
\hline Items used & Recruitment \\
\hline
\end{tabular}




\section{Design Experience (4)}

\begin{tabular}{|c|c|c|}
\hline Items used & Artwork & Recruitment \\
\hline & & \\
& &
\end{tabular}

Unit used: coincidence and circle repeated and distributed in proportion to the Fibonacci series

Functional dimension: Design of print suspended fabrics inside one of bahia hospital's detection rooms

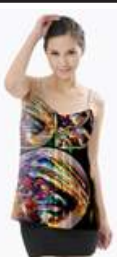

Functional dimension: Print design for evening fabrics for women in general and women with cancer patients in particular

\section{Design Experience (5)}

\begin{tabular}{|l|c|}
\hline Items used & Artwork \\
\hline Unit used: Multi-lobed vegetal leaves and petals of Islamic art have been repeated and distributed in \\
proportion to the Fibonacci series \\
Functional dimension: Design of print suspended fabrics inside one of bahia hospital's detection rooms
\end{tabular}

Design Experience (6)

\begin{tabular}{|l|l|l|}
\hline Items used & Artwork & Recruitment \\
\hline $\begin{array}{l}\text { Unit used: boxes and lines that have been repeated and distributed in proportion to the Fibonacci series } \\
\text { Functional dimension: Print design for morning women's fabrics in general and women with cancer } \\
\text { patients in particular }\end{array}$
\end{tabular}




\section{Design Experience (7)}

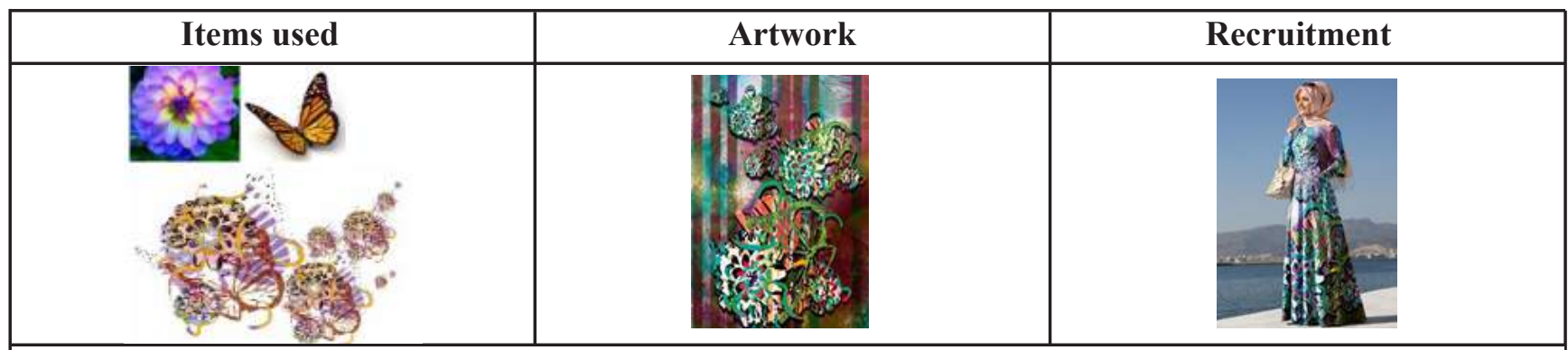

Unit used: Rose and butterfly have been repeated and distributed in proportion to the Fibonacci series Functional dimension: Print design for morning women's fabrics in general and women with cancer patients in particular

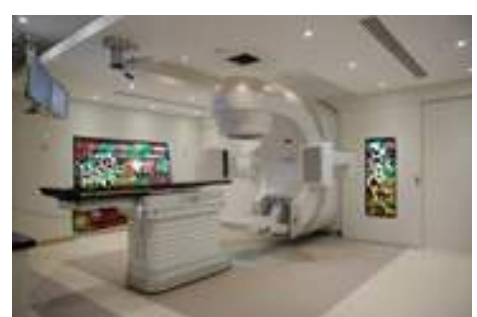

Functional dimension: Design of print suspended fabrics inside one of bahia hospital's detection rooms

\section{Design Experience (8)}

\begin{tabular}{|l|l|l|}
\hline Items used & Artwork & Recruitment \\
\hline
\end{tabular}

Unit used: Islamic cup was repeated and distributed in proportion to the Fibonacci series

Functional dimension: Print design for evening fabrics for women in general and women with cancer patients in particular

\section{Design Experience (9)}

\begin{tabular}{|c|c|c|}
\hline Items used & Artwork & Recruitment \\
\hline & & \\
\hline
\end{tabular}

The unit used: Islamic cup and triangles were repeated and distributed in proportion to the Fibonacci series Functional dimension: Print design for morning women's fabrics in general and women with cancer patients in particular 


\section{Design Experience (10)}

\begin{tabular}{|c|c|c|}
\hline Items used & Artwork & Recruitment \\
\hline & 0 & \\
\hline
\end{tabular}

Unit used: Islamic cup and circles repeated and distributed in proportion to the Fibonacci series

Functional dimension: Design of print suspended fabrics in one of bahia hospital corridors

\section{Design Experience (11)}

\begin{tabular}{|l|l|l|}
\hline Items used & Recruitment \\
\hline $\begin{array}{l}\text { The unit used: an Islamic cup and a snail that was repeated and distribluted in proportion to the Fibo- } \\
\text { nacci series } \\
\text { Functional dimension: Design of print suspended fabrics inside one of bahia hospital's detection rooms }\end{array}$
\end{tabular}

Design Experience (12)

\begin{tabular}{|l|l|}
\hline Items used & Artwork \\
\hline
\end{tabular}




\section{CONCLUSIONS \& FUTURE WORK}

- Monitoring the positive energy resulting from the diversity of distribution of natural and engineered elements using the Fibonacci series in the design of textile printing, and its use to support the psychological aspect of some cancer patients.

- Employing the technical capabilities of some computer programs to obtain innovative and unconventional design solutions as an aesthetic dimension to the development of printing designs.

- Take advantage of the general and successive Fibonacci mathematics in reaching new concepts for the basics of textile printing design.

- Solutions and design experiments for new construction shaping twelve design edited and employed by Bahia Hospital, and fabrics for women in general and women cancer patients to enrich the printing designs in general.

- More research and academic studies, and interest in the production of printing designs suitable for different functional purposes is required. Promoting art therapy in the field of textile printing design.

\section{References:}

1. Livio, Mario. The accelerating universe: infinite expansion, the cosmological constant, and the beauty of the cosmos. John Wiley \& Sons, 2001, p xiii.?

2. Nimkulrat, Nithikul, and Janette Matthews. "Mathematical textiles: the use of knot theory to inform the design of knotted textiles." (2013), p 2.]

3. Maha Mahmoud Ibrahim: "A New Formulation of Interior Design Elements from an Energy Science Perspective", Unpublished D.C., Faculty of Applied Arts, Helwan University, 2009.P. 51.

4. Abdul Wahid Al Khalil: "The Golden Percentage is the Source of Beauty and Inspiration”, Science and Technology Magazine, Year 29 Issue 114, Saudi Arabia, February 2015, p. 12.

5. Das, Sekhar, et al. "Potential of biomimicry in the field of textile technology." Bioinspired, Biomimetic and Nano biomaterials 6.4 (2017): 224-235, p 5.

6. Hussein Kamel al-Nabawi, et al.: "The Foundations of Bio-Composition Engineering Inspired by Ancient Egyptian Civilization", International Design Journal, Volume 6, Third Issue, July 2016, p. 299, 300.

7. Omotehinwa, T. O., and S. O. Ramon. "Fibonacci numbers and golden ratio in mathematics and science." International Journal of Computer and Information Technology (ISSN" 2279-0764) Volume (2013), p633.

8. Khaled Mustafa Fouad Youssef: "Green Architecture and Bioenergy Design", Master's Thesis (Unpublished), Department of Architecture, Faculty of Engineering, Cairo University, 2010, p. 61.

9. Lubna Abdel Aziz Ahmed Al-Barlsi: "The Ringing of Balance in Architecture and Urbanization”, Master's Thesis (Unpublished), Department of Architecture, Faculty of Engineering, Cairo University, 2007, p. 40.

10. Fallahpour, Mehdi, and David Megías. "Audio watermarking based on Fibonacci numbers." IEEE Transactions on Audio, Speech, and Language Processing 23.8 (2015): p1274.
11. MarwaMohieddin Hassan Ahmed Afi: "The Philosophical Dimension of Bio-Composition Engineering Data "Biogeomtri" as an Applied Entry into Decorative Design, Ph.D. (Unpublished), Department of Decorative Design, Faculty of Art Education, Helwan University, 2016, p. 76.

12. MahaSalaheddine, "The Relationship of Interior Design to Organic Architecture”, Ph.D., Department of Interior Design, Faculty of Applied Arts, Helwan University, 1995, p. 272.

13. Omotehinwa, T. O., and S. O. Ramon. "Fibonacci numbers and golden ratio in mathematics and science." International Journal of Computer and Information Technology (ISSN" 2279-0764) Volume (2013), p637?

14. Mohammed MohammedYousra Mahmoud Abdel Halim: "The philosophy of mathematical and engineering construction and its systems in contemporary photography as a source of inspiration for three-dimensional photography work", Ph.D. (unpublished), Department of Technical Education, Faculty of Quality Education, Cairo University, 2014, p. 18.

15. Islam Rafat Mohammed Al-Mursi: "Measuring the Vital Effects of The Elements of The Architectural Architectural Void", Unpublished Ph.D., Faculty of Engineering, Cairo University, 2014. P. 36.

16. JehanNaji: "The Effect of Plastic Vacuum Treatments on Humans", Unpublished M.A., Faculty of Engineering, Cairo University, 2002.P. 19.

17. Lamia Ibrahim Ahmed Abdel Fattah: "The possibility of dyeing natural silk fabrics with natural pigments to fit women's headgear", an unpublished (Master) thefaculty of Quality Education, University of Tanta, 2013.P2.

18. Mei Fayez Mohammed Shaheen: "Improving the stability of plant pigments on natural fibers using environmentally friendly materials", unpublished (Ph.D.) letter, Faculty of Applied Arts, Cairo University, 2006. P 64.

19. Samar Sharaf \& others, BhaarathiDhurai, "COMPARATIVE INVESTIGATIONS ON THE EFFICIENCY OF DIFFERENT ANCHORING CHEMICALS FOR THE PERMANENT FINISHING OF COTTON WITH CHITOSAN", AUTEX Research Journal, Vol. 11, No2, June 2011, p 76.

20. K. Karthikeyan, BhaarathiDhurai, "NEW METHOD OF DISCHARGE PRINTING ON COTTON FABRICS USING HORSERADISH PEROXIDASE", AUTEX Research Journal, Vol. 11, No2, June 2011, p 61.

21. Donna Radl, "EFFECTS OF ART THERAPY ON EMOTIONAL DISTRESS IN FEMALE CANCER PATIENTS", PhD Principal Investigator, Drexel University (Philadelphia),2015 p 8.

22. Noor Al-Hadi Abdul WadoodHallalZidan: "Carcinogenic Effects of Pesticides and Other Pollutants", Assiut Journal of Environmental Studies - January 32, 2008, p. 73.

23. KATHERINE BRANTNER, "ART THERAPY AND CANCER SUPPORT: PATIENT AND FAMILY", UNIVERSITY OF WISCONSIN SUPERIOR, p 54.

24. Diana C. Barnes, "HOW WOMEN USE ART TO COPE WITH BREAST CANCER", A Systematic Exploration of Published Literature" (may2015). Loyola Marymount University/LLS Theses and Dissertations, $\mathrm{p} 49$.

25.Shaimaa Sayed Kassem Khedr, "Strategic Approach to Designing Print Pendants asA Means of Communication with Egyptian International Airports", Master's Thesis (Unpublished), Textile Printing Department, Faculty of Applied Arts, Helwan University, 2015, p. 85. 